\title{
Chemical reduction of metal-organic frameworks as a method to enhance gas uptake and binding
}

\author{
Supporting Information \\ Karen L. Mulfort, Joseph T. Hupp* \\ Department of Chemistry, Northwestern University, Evanston, IL 60208
}

General information. Commercial reagents were purchased from Sigma-Aldrich (ACS grade) and used as received unless otherwise noted. Tetrahydrofuran (THF) and N,N'dimethylformamide (DMF) were purified using a two-column solid-state purification system (Glasscontour System, Jeorg Meyer, Irvine, CA). Elemental analyses were performed by Atlantic Microlabs, Inc. (Norcross, GA). Powder X-ray diffraction (PXRD) patterns were recorded with a Rigaku XDS 2000 diffractometer using nickel-filtered $\mathrm{Cu} \operatorname{K\alpha }$ radiation $(\lambda=$ $1.5418 \AA$ ) over a range of $5^{\circ}<2 \theta<40^{\circ}$ in $0.1^{\circ}$ steps with a 1 -s counting time per step. Powder samples were placed in the diffractometer mounted on a stainless steel holder with double-sided tape. Thermogravimetric analyses (TGA) were performed on a Mettler-Toledo TGA/SDTA851e. Samples $\left(3-5 \mathrm{mg}\right.$ ) in alumina pans were heated from $25^{\circ} \mathrm{C}$ to $700^{\circ} \mathrm{C}$ at $10^{\circ} \mathrm{C} /$ minute under $\mathrm{N}_{2}$. Inductively coupled plasma (ICP) spectroscopy was conducted on a Varian model ICP spectrometer that is equipped to cover the spectral range from 175 to $785 \mathrm{~nm}$. Samples (3-5 mg) were digested in $1: 1 \mathrm{H}_{2} \mathrm{SO}_{4}: \mathrm{H}_{2} \mathrm{O}_{2}$ and heated at $120^{\circ} \mathrm{C}$ until the solution became clear and colorless and no further vapor was produced. An aliquot of this concentrated acid solution was diluted to $5 \%$ in $\mathrm{DI} \mathrm{H}_{2} \mathrm{O}$ and analyzed for $\mathrm{Li}(610.365 \mathrm{~nm})$ and $\mathrm{Zn}(202.548$ $\mathrm{nm}$ ) content. Adsorption isotherms were measured with an Autosorb 1-MP from Quantachrome Instruments. Ultra-high purity grade nitrogen and hydrogen were used for all adsorption measurements.

Synthesis. The syntheses of $N, N$ '-Di-(4-pyridyl)-1,4,5,8-naphthalenetetracarboxydiimide $(\operatorname{diPyNI})^{1}$ and $\mathbf{1}^{2}$ have previously been reported. However, a large-scale method has been recently developed for framework reduction and gas adsorption measurements. A sample 
preparation follows: $\mathrm{Zn}_{2}\left(\mathrm{NO}_{3}\right) \cdot 6 \mathrm{H}_{2} \mathrm{O}$ (600mg, $\left.2.0 \mathrm{mmol}\right), \mathrm{H}_{2} \mathrm{NDC}$ ( $\left.87 \mathrm{mg}, 0.4 \mathrm{mmol}\right)$, diPyNI (170mg, $0.4 \mathrm{mmol}$ ), and 200ml DMF were added to a $500 \mathrm{ml}$ flat-bottom flask. The flask was sonicated until all contents were dissolved and placed in an $80^{\circ} \mathrm{C}$ oil bath for two days. The bright yellow crystalline product was removed from the flask, isolated via filtration, washed with DMF, and allowed to dry in air. $\mathrm{Zn}_{2}(\mathrm{NDC})_{2}(\mathrm{diPyNI})(\mathbf{1})$ recovered: $239 \mathrm{mg}, 18 \%$ yield based on zinc. Anal. calcd. for $1 \cdot 2 \mathrm{H}_{2} \mathrm{O}, \mathrm{C}_{48} \mathrm{H}_{28} \mathrm{~N}_{4} \mathrm{O}_{14} \mathrm{Zn}_{2}$ : C, 56.77; H, 2.78; N, 5.52. Found: C, 56.17; $\mathrm{H}, 2.81 ; \mathrm{N}, 5.58$. Phase purity was verified by PXRD and TGA (Figure S1).

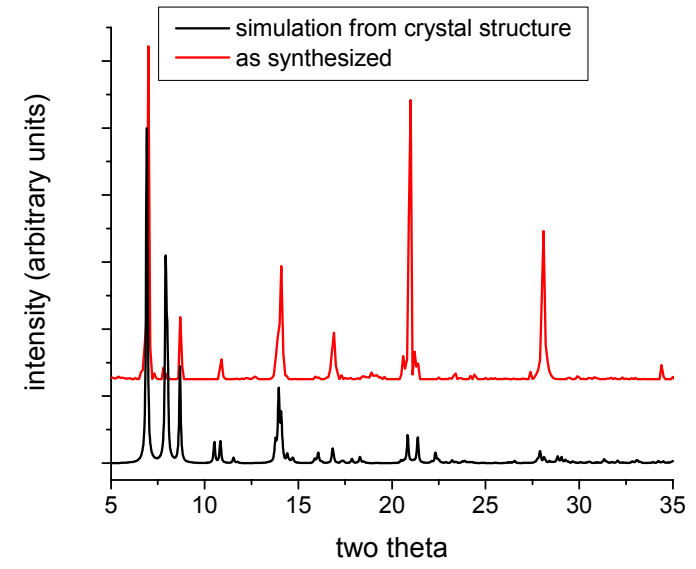

A

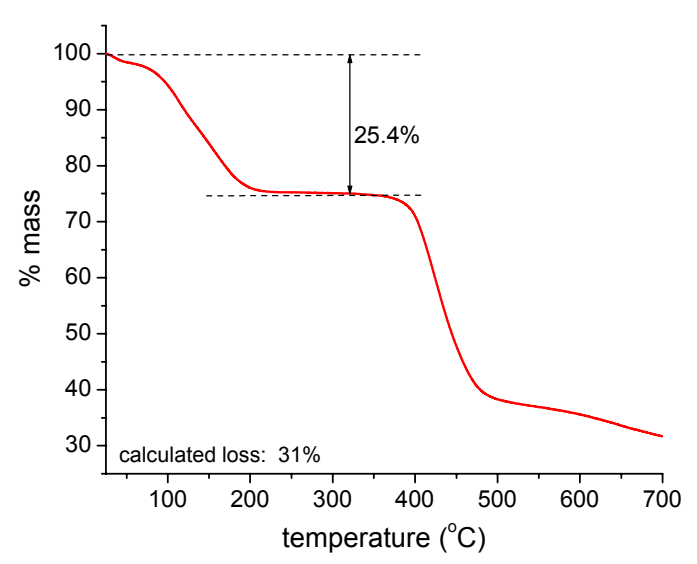

B

Figure S1. PXRD (A) and TGA (B) of 1.

Framework modification. All manipulations were carried out in an argon atmosphere glove box. A small piece of lithium metal (3.2mm wire in mineral oil) was immersed briefly in THF to remove excess mineral oil. Caution: Lithium metal is extremely reactive with water and potentially reactive with nitrogen! All manipulations with lithium metal were undertaken in an argon atmosphere glove box. Any dark oxide on the surface of the wire was scraped away. Lithium $(0.4 \mathrm{mg}, 0.057 \mathrm{mmol})$ was added to $5 \mathrm{ml}$ DMF in a round bottom flask. The lithium was allowed to interact with the DMF for one hour, in which time the solution became slightly cloudy, but the lithium was not completely dissolved. A sample of $\mathbf{1}(85 \mathrm{mg}, 0.065 \mathrm{mmol})$ was then added to the Li-DMF solution. The solution immediately turned from colorless to green and the solid from yellow to brown. The flask was manually agitated for 10 minutes and the solid was isolated on a coarse frit. The solid was washed with DMF $(10 \times 1 \mathrm{ml})$ and THF to dry $(2 \times 1$ $\mathrm{ml})$. The reduced sample, $\mathbf{1}^{-} \mathbf{L i}^{+}$, is air sensitive and will oxidize upon exposure to air, indicated 
by color change back to yellow. The $\mathrm{Li} / \mathrm{Zn}$ ratio in $\mathbf{1}^{-} \mathbf{L i}^{+}$was measured by ICP (Table S1). Anal. calcd. for $\mathbf{1}^{-} \mathrm{Li}^{+} \cdot 5 \mathrm{H}_{2} \mathrm{O}, \mathrm{C}_{48} \mathrm{H}_{24} \mathrm{~N}_{4} \mathrm{O}_{12} \mathrm{Li}_{0.06} \mathrm{Zn}_{2}$ : C, 53.88; H, 3.20; N, 5.24. Found: C, 53.86; H, 2.98; N, 5.21. PXRD and TGA of oxidized $\mathbf{1}^{-} \mathbf{L i}^{+}$were used to verify structural integrity through reduction and oxidation (Figure S2).

\begin{tabular}{|c|c|c|c|c|c|c|c|c|}
\hline & mol Li & $+/-$ & $\mathrm{mol} \mathrm{Zn}$ & $+1-$ & $\begin{array}{c}\mathrm{Li} / \mathrm{Zn} \\
\text { ratio }\end{array}$ & $+1-$ & $\begin{array}{c}\mathrm{Li} / \operatorname{diPyNI} \\
\text { ratio }\end{array}$ & $+/-$ \\
\hline 1 & $7.55 \times 10^{-11}$ & $6.37 \times 10^{-11}$ & $5.20 \times 10^{-8}$ & $3.70 \times 10^{-10}$ & 0.001 & 0.001 & 0.001 & 0.001 \\
\hline${ }^{1} \mathbf{L i}^{+}$ & $1.38 \times 10^{-8}$ & $1.00 \times 10-^{10}$ & $4.90 \times 10^{-7}$ & $7.75 \times 10^{-9}$ & 0.028 & 0.000 & 0.056 & 0.000 \\
\hline
\end{tabular}

Table S1. Summary of $\mathbf{1}$ and $\mathbf{1}^{\top} \mathbf{L i}^{+}$ICP results.

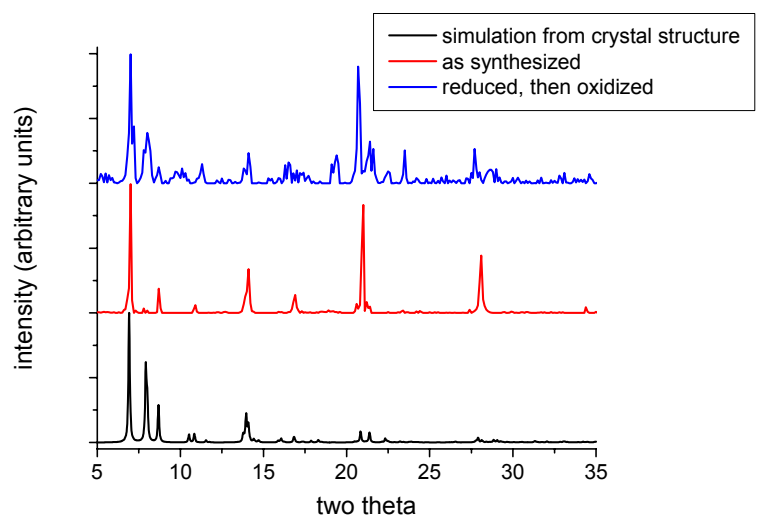

A

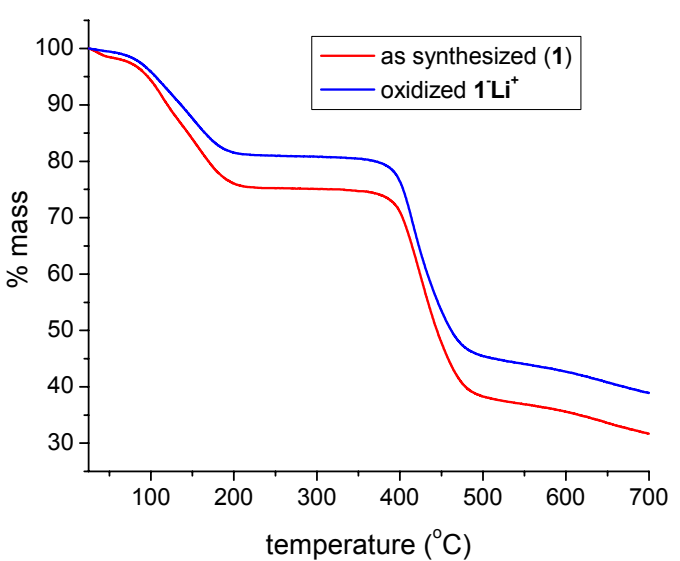

B

Figure S2. PXRD (A) and TGA (B) of $\mathbf{1}$ and oxidized $\mathbf{1}^{-} \mathbf{L i}^{+}$.

Adsorption measurements. Samples of a known weight (35-50 mg) were loaded into a sample tube and evacuated at $110^{\circ} \mathrm{C}$ under $10^{-5}$ torr dynamic vacuum for 24 hours on an Autosorb 1-MP prior to gas adsorption measurements. After evacuation, the sample and tube were precisely weighed again to obtain the evacuated sample weight. Samples of $\mathbf{1}^{-} \mathbf{L i}^{+}$were loaded into the sample tube in an argon atmosphere glove box and protected from air exposure until adsorption measurements. Nitrogen isotherms were collected at 77K. The BET surface area was determined in the range $0.007<\mathrm{P} / \mathrm{P}_{\mathrm{o}}<0.04$; the Dubinin-Raduskevich (DR) micropore volume was determined in the range $1 \times 10^{-5}<\mathrm{P} / \mathrm{P}_{\mathrm{o}}<0.01$ (Table S2). The hysteresis in the $\mathrm{N}_{2}$ adsorption isotherm was verified by cycling the adsorption/desorption isotherm twice (Figure S3). Hydrogen isotherms were collected at $77 \mathrm{~K}$ and $87 \mathrm{~K}$ (Figure S4). 


\begin{tabular}{lcc}
\hline & $\begin{array}{c}\text { BET surface area } \\
\left(\mathrm{m}^{2} / \mathrm{g}\right)\end{array}$ & $\begin{array}{c}\text { DR micropore volume } \\
\left(\mathrm{cm}^{3} / \mathrm{g}\right)\end{array}$ \\
\hline $\mathbf{1}$ & 802 & 0.30 \\
$\mathbf{1} \mathbf{L i}^{+}$ & 756 & 0.34 \\
\hline
\end{tabular}

Table S2. Summary of $\mathrm{N}_{2}$ adsorption results for $\mathbf{1}$ and $\mathbf{1}^{-} \mathbf{L i}^{+}$.

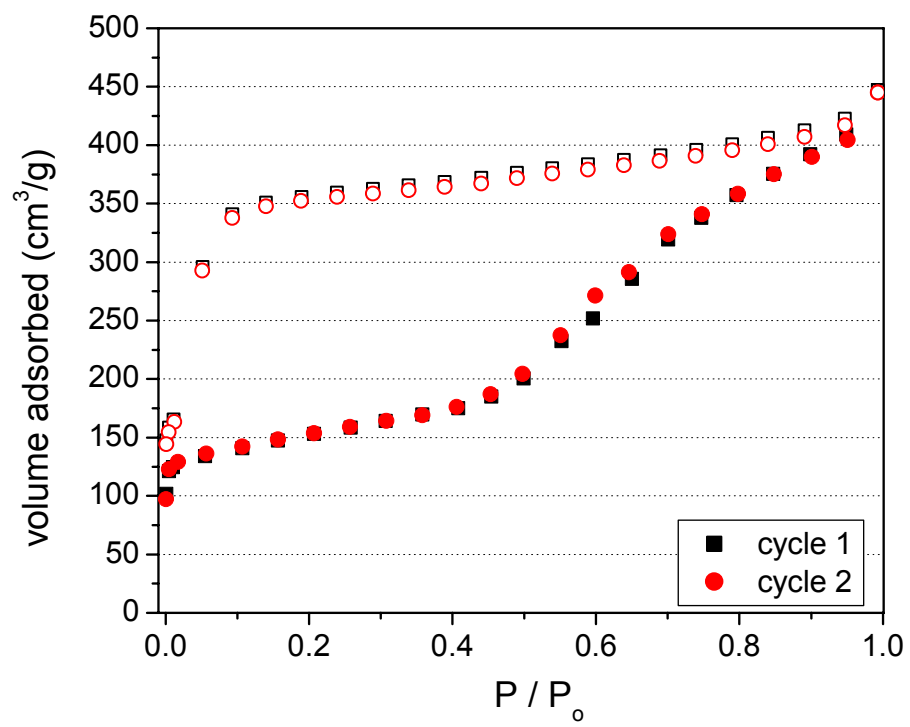

Figure S3. $\mathrm{N}_{2}$ adsorption/desorption cycles of $\mathbf{1}^{-} \mathbf{L i}^{+}$demonstrating repeatability of hysteresis. Closed symbols are adsorption, open symbols are desorption



A

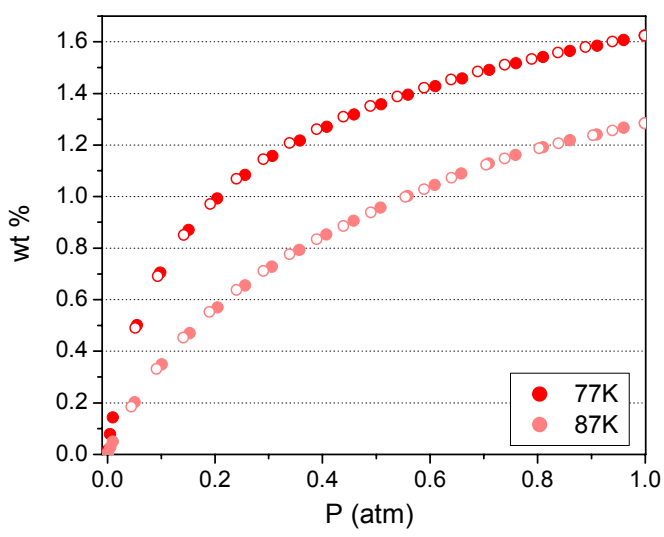

B

Figure S4. Hydrogen adsorption isotherms of $\mathbf{1}$ (A) and $\mathbf{1}^{-} \mathbf{L i}^{+}$(B) at $77 \mathrm{~K}$ and $87 \mathrm{~K}$. 
Isosteric heat of adsorption. Both hydrogen isotherms $(77 \mathrm{~K}, 87 \mathrm{~K})$ were fit to a virial equation of the form given in Equation 1. ${ }^{3}$ The heat of adsorption is then calculated from the fitting parameters using Equation 2. The isotherms and fitting parameters are shown in Figure S5.

$$
\begin{gathered}
\ln p=\ln N+\frac{1}{T} \sum_{i=0}^{m} a_{i} N^{i}+\sum_{i=0}^{n} b_{i} N^{i} \\
q_{s t}(N)=-R \sum_{i=0}^{m} a_{i} N^{i}
\end{gathered}
$$
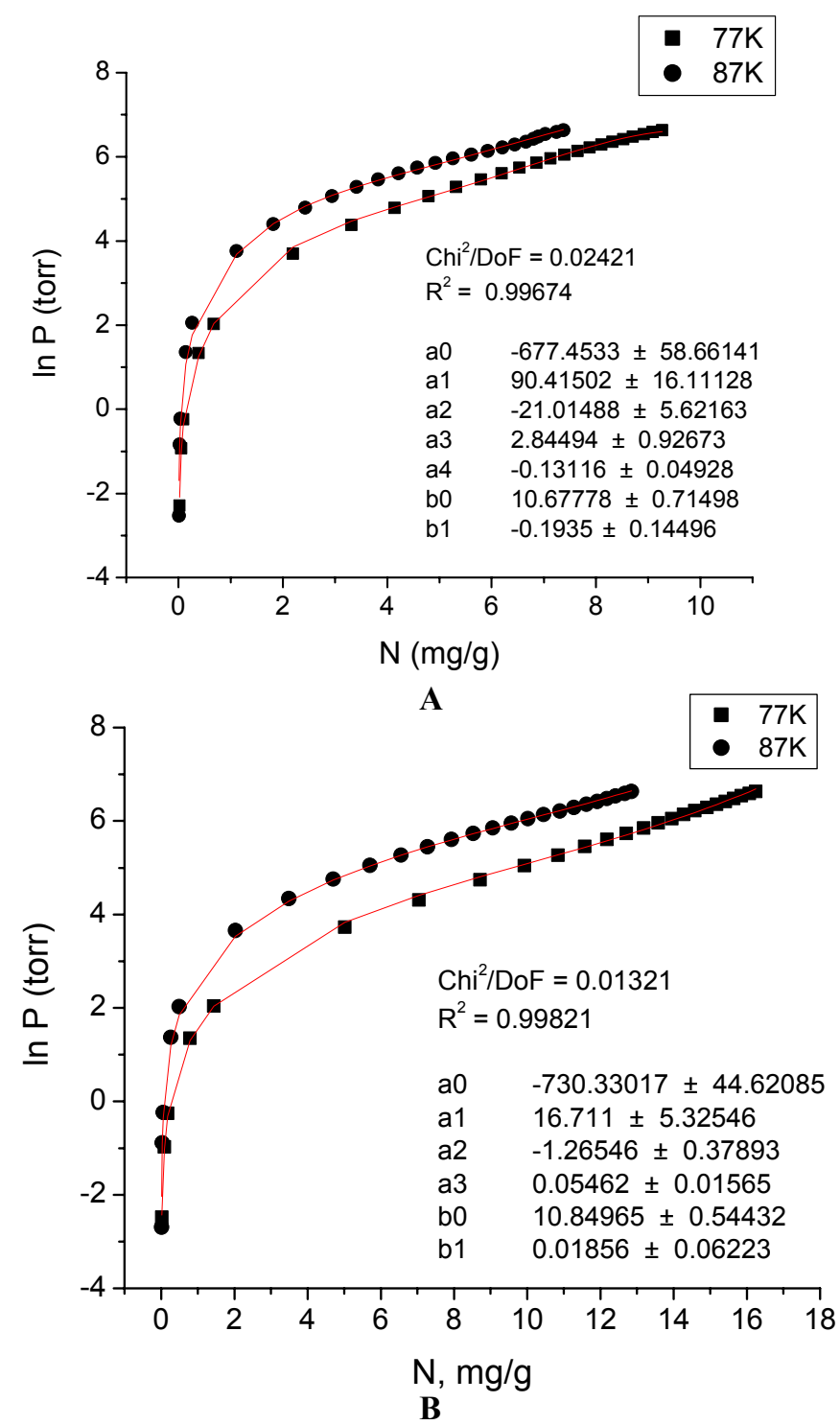

Figure S5. $\mathrm{H}_{2}$ isotherms at $77 \mathrm{~K}$ and $87 \mathrm{~K}$ (black symbols) and virial equation fits (red line) for $\mathbf{1}$ (A) and $\mathbf{1}^{-} \mathbf{L i}^{+}(\mathrm{B})$. 


\section{References}

(1) Dinolfo, P. H.; Williams, M. E.; Stern, C. L.; Hupp, J. T. Journal of the American Chemical Society 2004, 126, 12989-13001.

(2) Ma, B. Q.; Mulfort, K. L.; Hupp, J. T. Inorganic Chemistry 2005, 44, 4912-4914.

(3) Czepirski, L.; Jagiello, J. Chemical Engineering Science 1989, 44, 797-801. 